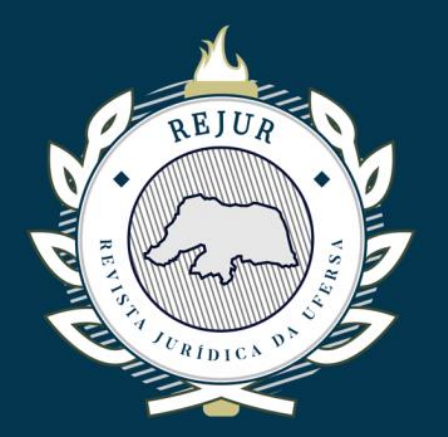

\title{
LA LIBERTAD DE EMPRESA $Y$ LA NO DISCRIMINACIÓN
}

BUSINESS FREEDOM AND NON DISCRIMINATION

\section{RESUMO $^{1}$}

Em uma análise do Direito argentino, o trabalho aborda o alcance e os limites do exercício do direito constitucional ao empreendimento econômico privado à luz do princípio da não discriminação nas relações de trabalho. Para tanto, investiga o leading case "Sisnero, Mirtha Graciela y otros" versus "Taldeva SRL y otros" e, pragmaticamente, ressalta a força normativa constitucional e convencional sobre as relações jurídicas entre particulares. Nessa finalidade, aborda relações entre a igualdade e a "não discriminação", a irradiação dos efeitos da "não discriminação" sobre relações jurídicas horizontais, a ponderação da discriminação inversa como medida de equidade e a posição da livre iniciativa em colisão com outros direitos positivos, de acordo com a jurisprudência argentina. Verifica que a irradiação de direitos fundamentais em todos os âmbitos do sistema jurídico inclui, também, a difusão de um princípio de justiça exigida pelo Estado de Direito constitucional.

Palavras-chave: Liberdade de empresa; Discriminação; Relações laborais.

\section{ABSTRACT $^{2}$}

In an analysis of Argentine law, the paper talks about the scope and limits of the exercise of constitutional law to the private economic enterprise against the principle of non-discrimination in labor relations. In order to do so, it investigates the leading case "Sisnero, Mirtha Graciela and others" versus "Taldeva SRL y otros" and pragmatically highlights the constitutional and conventional normative force on legal relations between individuals. To this end, it addresses the relationship between equality and nondiscrimination, the irradiation of the effects of 'nondiscrimination' on horizontal legal relationships, the consideration of reverse discrimination as a measure of equity and the position of free initiative in collision with other rights, according to the jurisprudence of Argentina. Finally, it notes that the dissemination of fundamental rights in all areas of the legal system also includes the dissemination of a principle of justice required by the constitutional State of Law.

Keywords: Freedom of business; Discrimination; Work relationships.

* Doutor em Direito pela Universidad Complutense de Madrid, Espanha (UCM).

Professor Adjunto da Universidad de Buenos Aires (UBA). Advogado.

ccao@derecho.uba.ar

Recebido em 11-5-2017 | Aprovado em 11-5-2017³

\footnotetext{
${ }^{1}$ Elaborado pelos Editores.

2 Elaborado pelos Editores.

${ }^{3}$ Artigo convidado. Publicação original: LA LEY 30/06/2014, 6 - LA LEY2014-D, 55
} 


\section{SUMÁRIO}

INTRODUCCÍON: LOS HECHOS DEL CASO; 1 EL DERECHO CONSTITUCIONAL A LA EMPRESA

ECONÓMICA Y SUS LÍMITES; 1.1 Los límites al ejercicio de los derechos económicos de producción: jurisprudencia; 2 LA IGUALDAD Y LA NO DISCRIMINACIÓN; 3 IRRADIACIÓN DE LOS EFECTOS DE LA NO DISCRIMINACIÓN EN LAS RELACIONES JURÍDICAS HORIZONTALES; 4 LA DISCRIMINACIÓN INVERSA COMO MEDIDA DE EQUIDAD; 5 COLISIÓN DE RECHOS. LIBERTAD DE EMPRESA Y SU LÍMITE EM LA NO DISCRIMINACIÓN: ESTÁNDARES JURISPRUDENCIALES ALCANZADOS

\section{INTRODUCCÍON: LOS HECHOS DEL CASO}

En autos 4 "Sisnero, Mirtha Graciela y otros c/ Taldelva SRL y otros s/ amparo" de fecha 20 de mayo de 2014, la Corte Suprema de Justicia de la Nación en el entendimiento de un recurso de queja, abordó el alcance y los límites del ejercicio del derecho constitucional al emprendimiento económico privado a la luz del principio de no discriminación.

Al dejar sin efecto la sentencia inferior, el máximo juzgador hizo lugar a la amparista afectada en el ejercicio de su oportunidad a acceder o elegir libremente un trabajo por motivos discriminatorios.

El interés del comentario radica en la interpretación que hace el máximo tribunal sobre el ejercicio de un derecho - de jerarquía constitucional-, al tiempo que ese despliegue afecta un interés jurídico de otra persona debido a su irracionalidad.

Este aporte casuístico contribuye, junto con otros que también serán reseñados, a consolidar la fuerza normativa constitucional y convencional sobre las relaciones jurídicas entre particulares.

\section{EL DERECHO CONSTITUCIONAL A LA EMPRESA ECONÓMICA Y SUS LÍMITES}

La Constitución Nacional reconoce un grupo de derechos preponderantemente económicos que giran alrededor de la esfera de la libertad ${ }^{5}$ con relación a la producción y el intercambio de bienes y/o servicios con valor agregado, y que a su vez presuponen la existencia del derecho de propiedad privada.

A este conjunto de derechos que forman parte de la Constitución socioeconómica, propuse denominarlo bloque de derechos económicos de producción ${ }^{6}$.

¿Cómo se encuentra conformado el conjunto de derechos agrupado en ese bloque económico de producción?

\footnotetext{
${ }^{4}$ Corte Suprema de Justicia de la Nación 2014-05-20 Sisnero, Mirtha Graciela y otros c. Tadelva SRL y otros s/ amparo.

${ }^{5}$ BIDART CAMPOS, Germán. Tratado elemental de derecho constitucional argentino. t. I-B. Buenos Aires: Ediar, 2000 ?, p. 45.

${ }^{6} \mathrm{CAO}$, Christian. Constitución socioeconómica y derechos fundamentales. Estudio comparado entre los casos de España y Argentina. 2013. Tesis (Doctorado en Derecho) -Universidad Complutense de Madrid, Madrid. 2013, p. 303 y ss. En formato digital: http://cisne.sim.ucm.es/
} 
Expresamente reconocidos se encuentran:

i) El derecho de ejercer industria lícita (artículo 14 de la Constitución nacional);

ii) El derecho de comerciar (artículo 14);

iii) El derecho de ejercer una profesión autónoma o trabajo, o bien desarrollar un emprendimiento económico por cuenta propia (artículo 20).

Si bien la doctrina en general reconoce sus presencias en el texto supremo, ella no suele utilizar con frecuencia el concepto de "libertad de empresa" o "derecho de empresa"7.

La jurisprudencia, en cambio, cumplió un papel fundamental para determinar la naturaleza jurídica del derecho o bloque de derechos de producción referidos al libre emprendimiento económico privado al ejemplificarlos. Entre ellos se destacan casos de ejercicio de profesiones autónomas ${ }^{8}$, venta de medicamentos ${ }^{9}$, e incluso la actividad de otorgamiento de préstamos pignoraticios ${ }^{10}$, entre tantos otros. Más recientemente y continuando con enumeraciones, la Corte Suprema de Justicia de la Nación tuteló el ejercicio del derecho económico "a trabajar" - con relación a una actividad autónoma, como es la registración notarial - frente a reglamentaciones irrazonables reconociendo así un verdadero "derecho a tener la oportunidad de ganarse la vida mediante un trabajo digno"11. Conforme lo entendió aquel Tribunal, a esa actividad, que no importa un trabajo dependiente sino uno de carácter autónomo, le caben los beneficios que aseguran los derechos sociales establecidos en la Constitución nacional.

Así, las distintas sub denominaciones usadas por la doctrina y la jurisprudencia argentinas para definir la libertad económica productiva - sea derecho de realizar un trabajo autónomo o profesión, comerciar o ejercer industria lícita- encuentran pocos elementos diferenciadores de relevancia.

Las diversas fórmulas constitucionales utilizadas por el constituyente argentino que componen el bloque de derechos económicos de producción, bien podrían ser unificadas en una sola noción. Por ejemplo, y tal como se observa en ordenamientos constitucionales

\footnotetext{
${ }^{7}$ Por ejemplo, EKMEKDJIÁN, Miguel. Tratado de derecho constitucional. t. I. Buenos Aires: Depalma, 1993, p. 493; PÉREZ HUALDE, Alejandro. Constitución y economía. Buenos Aires: Depalma, 2000, p. 68; QUIROGA LAVIÉ, Humberto. Lecciones de derecho constitucional. Buenos Aires: Depalma, 1995, p. 221- 222; entre otros.

${ }^{8}$ Sentencia de la Corte Suprema de Justicia de la Nación "D. Francisco Arcelus contra Casimiro Gómez, por liquidación social y rendición de cuentas s/ capacidad de la mujer para ejercer la procuración judicial" (Fallos 42:274) de 21 de febrero de 1891 y sentencia de la Corte Suprema de Justicia de la Nación "Doctor don Miguel Angel Angulo y García, reclamando una resolución de la Excma. Cámara de Apelaciones en lo Civil s/ prohibición de informar in voce por no ser abogado inscripto en la matrícula, y no haber prestado el juramento de ley" (Fallos 65:58) de 1 de septiembre de 1896.

${ }^{9}$ Sentencia de la Corte Suprema de Justicia de la nación "Departamento Nacional de Higiene c/ Indraccolo Sauver s/ venta de específico" (Fallos 115:82) de 30 de noviembre de 1911.

${ }^{10}$ Sentencia de la Corte Suprema de Justicia de la Nación "José Ferry s/ infracción ley 4531" (Fallos 124:402) de 9 de diciembre de 1916.

11 Sentencia de la Corte Suprema de Justicia de la nación "Jiménez, María c/ Provincia de Salta s/ inconstitucionalidad", de 19 de abril de 2011, con comentario de: CAO, Christian. El derecho a ganarse la vida mediante un trabajo y las reglamentaciones irrazonables. In: Revista Jurídica La Ley, Buenos Aires, 2011-B, p. 658 y ss.
} 
contemporáneos, es posible enumerar el derecho "a la libertad de empresa", "la libertad para desarrollar una actividad económica", "la libre iniciativa económica", entre tantos otros ${ }^{12}$.

Se debe reconocer que estos conceptos jurídico-económicos se ajustan mejor a las sociedades constitucionales contemporáneas, que se desenvuelven en el marco de modelos de mercado mediante la producción y el intercambio de bienes y servicios, a su vez resguardando los valores sociales.

En el caso argentino resulta válido aludir a otros tipos de formulas jurídicas que valoren el ejercicio de la iniciativa económica productiva privada, siempre que se observe la coherencia y cohesión interna del bloque de derechos económicos de producción.

En el derecho constitucional argentino es posible reconocer - a partir de esta construcción - la existencia de un derecho a la libre iniciativa económica privada (con sus especificidades, similar a la reconocida en el artículo 41 de la Constitución italiana de 1947 o en el artículo 85 inciso 1 de la Constitución de Portugal de 1976), e incluso - de forma innominada - la libertad de empresa (también con sus especificidades, similar a la recogida por el artículo 38 de la Constitución española) o el derecho al desarrollo de la unidad de negocio productivo.

En síntesis, sostengo que la Constitución socioeconómica argentina reconoce un derecho subjetivo al emprendimiento económico privado, o simplemente denominada libertad de empresa.

\subsection{Los límites al ejercicio de los derechos económicos de producción: jurisprudencia}

Los derechos constitucionales económicos obviamente no son absolutos y por lo tanto sus reglamentaciones pueden y deben limitar su contenido con relación al resto de los derechos fundamentales. Aquellos bienes jurídicos que integran el bloque económico de producción dentro de la Constitución socioeconómica argentina (en sus variantes libertad de comercio, industria o trabajo autónomo o profesión) no son ajenos a esta apreciación.

Se aplican aquí los parámetros sobre el principio de reserva de ley (artículos 14 y 19 de la Constitución argentina) y razonabilidad de la reglamentación (artículo 28 de la misma norma) al ejercicio del derecho.

Justamente la construcción jurisprudencial ha establecido bases para la aplicación del criterio de razonabilidad en la limitación de la libertad económica. El máximo tribunal de justicia, siguiendo criterios pretorianos norteamericanos, y en relación con la limitación reglamentaria sobre la industria agroalimentaria (clasificación y tipo de ganado, carnes, productos y subproductos de ganadería, transporte, explotación e incluso propaganda), hace décadas se preguntaba: "¿Qué es esta libertad? La Constitución no habla de libertad (freedom) de contratar. Habla de libertad (liberty) y prohíbe la privación de esta libertad sin el debido procedimiento legal. Al prohibir dicha privación, la Constitución no reconoce una libertad

\footnotetext{
12 Ver la sustancial compilación de terminologías empleadas por las Constituciones miembros del Consejo de Europa para la referencia al mismo derecho - aunque incidiendo en su radio de acción - realizada por Ignacio GARCÍA VITORIA en; La libertad de empresa: ¿un terrible derecho?, Centro de Estudios Políticos y Constitucionales, Madrid, 2008, Pág. 140 (nota al pie de página).
} 
absoluta e incontrolable. La libertad en cada una de sus fases tiene su historia y connotación. Pero la libertad salvaguardada es la libertad que en una organización social, requiere la protección de la ley contra los males que amenazan la salud, seguridad, moral y bienestar del pueblo. La libertad según la Constitución está, pues, necesariamente sujeta a las restricciones del debido procedimiento, y una regulación que sea razonable con relación a su objeto y se adopte en el interés de la comunidad, equivale a dicho debido procedimiento"13.

De esta forma y a criterio jurisprudencial, las eventuales limitaciones a los derechos económicos de producción sólo pueden caber en un marco de racionalidad ponderada.

Así lo entendió el tribunal judicial en uno de sus primeros casos referido a la matriculación obligatoria para el ejercicio de ciertas profesiones ${ }^{14}$, o que requerían una "comprobación del conjunto de conocimientos indispensables" 15 o la atención de "delicadas funciones" que exigía la profesión ${ }^{16}$, o la prohibición de bonificar con sueldos mayores a las categorías inferiores en situación jerárquica (fijación de sueldos mínimos) en aras de lograr una "ordenada coexistencia de las oficinas y la tranquilidad en la prestación de las obligaciones laborales"17.

Más polémicos fueron los casos en los cuales, a los fines de determinar la razonabilidad de la reglamentación (y por lo tanto su constitucionalidad), el factor determinante giró en torno a la exigencia de ausencia de antecedentes policiales para obtener habilitaciones comerciales ${ }^{18}$, la fijación de precios máximos de venta de bienes (en situaciones de emergencia o períodos de guerra) ${ }^{19}$, o la participación compulsiva y obligatoria de productores vitivinícolas a una entidad mediante un aporte que los convertía en socios ${ }^{20}$.

La enumeración de ejemplos puede continuar sobre numerosas materias que rodean la libertad constitucional de empresa, pero a la hora de limitar el ejercicio de este derecho resulta necesario observar la garantía de la totalidad de los derechos fundamentales de forma proporcionalmente ponderada.

\footnotetext{
${ }^{13}$ Sentencia de la Corte Suprema de Justicia de la Nación "Pedro Inchauspe Hnos. c/ Junta Nacional de Carnes s/ devolución de pesos" (Fallos 199:516) de 1 de septiembre de 1944. El subrayado es agregado.

${ }^{14}$ Sentencia de la Corte Suprema de Justicia de la Nación "Doctor don Miguel Angel Angulo y García, reclamando una resolución de la Excma. Cámara de Apelaciones en lo Civil s/ prohibición de informar in voce por no ser abogado inscripto en la matrícula, y no haber prestado el juramento de ley" (Fallos 65:58) de 1 de septiembre de 1896.

${ }^{15}$ En el caso, ciencias económicas, actuario y contador público. Sentencia de la Corte Suprema de Justicia de la Nación "Solivellas, Vicente s/ apela resolución del Consejo Profesional de Ciencias Económicas" (Fallos 214:612) de 26 de septiembre de 1949, a modo de ejemplo.

${ }^{16}$ En el caso, actividad de notario público. Sentencia de la Corte Suprema de Justicia de la Nación "Almada, Edgardo s/ información" (Fallos 268:91) de 16 de junio de 1967.

${ }^{17}$ Sentencia de la Corte Suprema de Justicia de la Nación "Barone, Manlio y Cajarville, Jesús c/ Banco di Nápoli" (Fallos 249:252) de 10 de marzo de 1961.

${ }^{18}$ En el caso, se rechazó la habilitación de apertura de un club nocturno. Sentencia de la Corte Suprema de Justicia de la Nación "Miranda, R. y otros s/ recurso de amparo" (Fallos 257:30) de 9 de octubre de 1963.

${ }^{19}$ Sentencia de la Corte Suprema de Justicia de la Nación "Martini Vicente e hijos (S.R. Ltda.) s/ infracción ley 12.591" (Fallos 200:250) de 27 de diciembre de 1944.

${ }^{20}$ Sentencia de la Corte Suprema de Justicia de la Nación "Cavic c/ Maurín y Cía. SRL" de 8 de julio de 1970.
} 


\section{LA IGUALDAD Y LA NO DISCRIMINACIÓN}

Se ha dicho que del derecho a la libertad se desprende la igualdad ${ }^{21}$, sea como principio general o como derecho público subjetivo, el cual importa un trato justo a todas las personas.

La recepción constitucional de la igualdad de sus artículos 15 -prohibición de esclavitud- y 16 -igualdad ante la ley - se completa con el igual reconocimiento de derechos a todas las personas - artículo 14, entre otros-, incluyendo a los extranjeros artículo 20-, y se integra en su función social con acciones positivas, a las cuales me referiré más adelante al analizar las proyecciones de la sentencia bajo análisis.

En el mismo orden de ideas, la no discriminación suele configurársela como una superación del derecho a la igualdad, por la cual la norma apunta a interdictar criterios, categorías o clasificaciones inmotivadas, arbitrarias o irrazonables.

De esta manera, el derecho a la no discriminación apunta a reconocer primeramente la igualdad de la persona frente al Estado y la ley, y además a abogar por el respeto de las diferencias (derecho a ser diferente), sean naturales o culturales.

Suele apuntarse que este derecho es en rigor tuitivo de otros, más que uno en sí mismo, ya que cumple el rol de una norma de cierre del paradigma constitucional que interdicta criterios diferenciadores irracionales ${ }^{22}$.

Relacionado con la autonomía y libertad de la persona, el Estado debe entonces garantizar la no discriminación desde una dimensión negativa -es decir, no interferir en las decisiones o plan de vida de las personas ${ }^{23}-$, y desde una dimensión positiva -esto es, suministrar las condiciones para que la persona pueda desarrollar su libre personalidad ${ }^{24}$.

Desde el plano internacional del derecho, jerarquizado constitucionalmente en virtud de su artículo 75 inciso 22, estos lineamientos también fueron recogidos en instrumentos jurídicos. Veamos un sintético panorama.

La Convención Americana sobre Derechos Humanos, establece un mandato a los Estados parte: respetar los derechos allí reconocidos y garantizar su libre y pleno ejercicio "sin discriminación alguna por motivos de raza, color, sexo, idioma, religión, opiniones políticas o de cualquier otra índole, origen nacional o social, posición económica, nacimiento o cualquier otra condición social".

En primer lugar, la norma refiere a la obligación de los Estados de respetar los derechos humanos reconocidos en el Pacto de San José de Costa Rica sin discriminación alguna, implicando que toda relación jurídica debe ser desplegada observando el principio de

\footnotetext{
${ }^{21}$ BIDART CAMPOS, op. cit., p. 71.

${ }_{22}^{2}$ GIL DOMínGUEZ, Andrés. Escritos sobre neoconstitucionalismo. Buenos Aires: Ediar, 2009, p. 293.

${ }^{23}$ Por ejemplo y sobre la prohibición de interferir en el plan de vida de las personas en relación a los derechos a la vida y la salud - Albertus, Viviana y Cao, Christian; "Libertad de intimidad y derecho a la salud. El respeto al plan de vida de las personas en la Constitución nacional (a propósito de la transfusión de sangre y la vacunación obligatoria)", Revista Jurisprudencia Argentina, JA 2012-III-Pág. 20.

${ }^{24}$ Ampliar en: GUASTINI, Riccardo. Distinguiendo. Estudios de teoría y metateoría del derecho. Barcelona: Ariel, 1999, p. 197.
} 
la no discriminación, sean estas verticales (Estado y particulares) u horizontales (particulares entre sí).

En segundo lugar, si bien los parámetros de discriminación interdictados se encuentran enumerados, la norma deja abierta una cláusula de "cualquier otra condición social", a los fines de eventualmente añadir otros allí no recogidos cuya sintomática sea actual o futura.

Iguales recepciones se observan en el Pacto Internacional de Derechos Económicos, Sociales y Culturales (artículo 2, inciso 2, "sin discriminación") y el Pacto Internacional de Derechos Civiles y Políticos (artículos 2 inciso 1, "sin distinción").

En síntesis, la interdicción de la discriminación o de la distinción irrazonable constituye el marco dentro del cual deben desarrollarse las relaciones jurídicas en un Estado constitucional y convencional de derecho.

\section{IRRADIACIÓN DE LOS EFECTOS DE LA NO DISCRIMINACIÓN EN LAS RELACIONES JURÍDICAS HORIZONTALES}

El constitucionalismo clásico se ocupó de estructurar, junto con la división de poderes, el reconocimiento de un espectro de derechos frente al poder público. En Europa antes del constitucionalismo se buscó modificar la cosmovisión del poder, organizándolo de una manera diferente al que regía en el Ancien Régime: El Estado constitucional de derecho.

Sin embargo, aquella visión apuntó primordialmente a la limitación del poder en el Estado, aplicando los derechos en relaciones verticales. Esto es: Estado y persona.

En este orden de ideas, el principio de igualdad se tradujo en el derecho de igualdad ante la ley.

La Declaración de los Derechos del Hombre y del Ciudadano (1789) en su artículo 1 dispone que "Los hombre nacen y viven libres e iguales en derechos. Las distinciones sociales sólo pueden fundarse en utilidad común" ${ }^{25}$. La influencia de este artículo a nivel comparado conforma un dogma permanente del Estado constitucional ${ }^{26}$.

Frente a esta posición clásica constitucional, la visión superadora o neoconstitucionalista sostiene - consolidando ello- la irradiación los efectos de los derechos públicos subjetivos a las relaciones jurídicas horizontales.

\footnotetext{
${ }^{25}$ En relación a ello, el artículo 6 también refiere al principio de igualdad ante la ley. Para un estudio sobre esta declaración, la Declaración de Virginia y la de otros Estados norteamericanos, y el Bill of Rigths inglés (1689), ver: JELLINEK, Georg. La Declaración de los Derechos del Hombre y del Ciudadano. México: Universidad Nacional de México, 2000 [1895]. A su vez y del mismo autor, ampliar en: Teoría general del Estado, Editoriales B de F y Albatros 2005 [1905], Pág. 625 y ss.

26 HÄBERLE, Peter. Libertad, igualdad, fraternidad: 1789 como historia, actualidad y futuro del Estado constitucional. Madrid, Editorial Trotta, 1998, p. 49 y ss.
} 
Esto no es otra cosa que la aplicación de la fuerza normativa de la Constitución a todo tipo de relaciones jurídicas, no sólo las relaciones jurídicas verticales, sino también las relaciones entre particulares ${ }^{27}$.

En la doctrina europea esta problemática fue planteada hace tiempo, a partir de un caso de la jurisprudencia alemana ${ }^{28}$. Allí se ha expuesto que la garantía constitucional de los derechos individuales no se agota en la de clásicos derechos de defensa del ciudadano frente al Estado, sino encarna un orden objetivo de valores (objektive Wertordnung) con la consecuencia de que "los valores o principios fundamentales no valen únicamente para la relación entre el Estado y el ciudadano, sino para todos los ámbitos del Derecho".

En el ámbito convencional (artículo 64 de la Convención Americana sobre Derechos Humanos, cfr. Artículo 75 inciso 22 de la Constitución nacional), la Opinión Consultiva 18/03, citada en la sentencia que seguidamente abordaré, ha trazado criterios interpretativos sobre la teoría de la irradiación de los efectos de los derechos fundamentales entre particulares, o eficacia de los derechos fundamentales entre privados.

Así, el desafío planteado por el caso "Sisnero" proponer extender el alcance de los derechos fundamentales también a las relaciones jurídicas horizontales.

\section{LA DISCRIMINACIÓN INVERSA COMO MEDIDA DE EQUIDAD}

La reforma de la Constitución nacional del año 1994 incorporó el principio de "discriminación inversa", instrumentada por el Estado en acciones positivas que imponen cuotas, cupos $u$ otros beneficios a diversos colectivos minoritarios o anteriormente injustamente discriminados.

La discriminación inversa persigue alcanzar -o al menos tender hacia- una reparación histórica a grupos anteriormente discriminados, y/o para construir una sociedad más justa e integrada ${ }^{29}$.

Algunos ejemplos de acciones positivas se encuentran recogidas en los artículos 37 (igualdad de oportunidades políticas entre hombres y mujeres), 38 (participación de las posiciones minoritarias en los partidos políticos), 75 inciso 17 (tutela económico-cultural para los pueblos indígenas) de la Constitución Nacional.

Sin dudas la previsión del artículo 75 inciso 23 de la Constitución Nacional, curiosamente no citado en la sentencia bajo análisis, importa el principal fundamento de las acciones positivas.

\footnotetext{
${ }^{27}$ BIDART CAMPOS, Germán. El derecho de la Constitución y su fuerza normativa. Buenos Aires: Ediar, 1995, p. 152.

${ }^{28}$ Sentencia del Tribunal Constitucional Alemán de 1958, "Lüth, Erich (recurre sentencia del Tribunal Estatal de Hamburgo)", BVerfGE 7, 198, en la cual también se destaca que "Los derechos fundamentales son ante todo derechos de defensa del ciudadano en contra del Estado; sin embargo, en las disposiciones de derechos fundamentales de la Ley Fundamental se incorpora también un orden de valores objetivo, que como decisión constitucional fundamental es válida para todas las esferas del derecho". El subrayado es agregado.

${ }^{29}$ SAGÜÉS, Néstor. Elementos de Derecho Constitucional. t. II. Buenos Aires, Astrea, 1997, p. 447.
} 
La norma impone al Congreso de la Nación, el deber de "legislar y promover medidas de acción positiva que garanticen la igualdad real de oportunidades y de trato, y el pleno goce y ejercicio" de los derechos fundamentales.

Estas medidas de acción positiva deben otorgarse en particular respecto los siguientes colectivos sociales:

- los niños;

- las mujeres;

- los ancianos;

- las personas con discapacidad.

De esta manera, el constituyente de 1994 identificó cuatro grupos sociales - o cinco, si se quiere añadir los pueblos indígenas (inciso 17) - , a los cuales la normativa jurídica debe ser centro de imputación de los beneficios, o, derechos a acciones positivas fácticas y/o normativas ${ }^{30}$.

Uno de esos colectivos - las mujeres - conforma el punto de apoyo por el cual en el caso "Sisnero" el juzgador, al promocionar la real igualdad de oportunidades, sopesó la pretensión de la accionante por sobre el interés del demandado.

\section{COLISIÓN DE DERECHOS. LIBERTAD DE EMPRESA Y SU LÍMITE EN LA NO DISCRIMINACIÓN: ESTÁNDARES JURISPRUDENCIALES ALCANZADOS}

¿Cómo conjugar el ejercicio de uno de los contenidos de la libertad de empresa contratar a un determinado trabajador dependiente- con el principio y el derecho a la igualdad y a la no discriminación?

La irradiación de los derechos fundamentales en todos los ámbitos del sistema jurídico incluye también la difusión del principio de justicia exigida por el propio Estado de derecho constitucional.

Consecuentemente, la colisión del ejercicio de derechos encuentra su solución más adecuada en la aplicación de una razonable ponderación. A esto se le debe agregar los mandatos constitucionales que imponen la instrumentación de medidas de acción positiva, explicadas en párrafos anteriores.

Dentro de ellas se desacata la promoción real de oportunidades a recurrente: una mujer agraviada en su ejercicio de elegir libremente y sin discriminación un empleo, en el caso, conductora de colectivos.

Cabe recordar que en el plano de las relaciones jurídicas verticales (relación Estadoparticulares), la Corte Suprema de Justicia ya había consolidado el principio de igualdad y no discriminación en materia de empleo o cargos públicos ${ }^{31}$.

\footnotetext{
${ }^{30}$ ALEXY, Robert. Teoría de los derechos fundamentales. Madrid: Centro de Estudios Políticos y Constitucionales, 1993, p. 195 y ss y 419 y ss.

${ }^{31}$ Respectivamente, sentencia de la Corte Suprema de Justicia de la nación "Arenzón, Gabriel Darío c./Nación Argentina" de fecha 01/01/1984 (Fallos 306:400) y sentencia de la Corte Suprema de Justicia de la nación "Hooft, Pedro c/ Provincia de Buenos Aires" de fecha 16/11/2004, entre otros.
} 
En referencia con las relaciones jurídicas horizontales, el pronunciamiento judicial reseña el antecedente "Alvarez, Maximiliano y otros c/ Cencosud SA" en donde el Tribunal ha dicho que "Es compatible - en el caso - la reinstalación del trabajador víctima de un distracto discriminatorio por su actividad sindical y el derecho a contratar y ejercer toda industria lícita del art. 14 de la Constitución Nacional, en virtud del singular motivo de ruptura del contrato de trabajo: la discriminación, pues cuando la libertad de contratar del empleador entra en conflicto con la libertad contra la opresión del empleado, esta última debe prevalecer sobre aquélla, porque así lo requieren los principios que fundan un ordenamiento social justo, toda vez que no otro es el sentido de la cláusula que los Constituyentes de 1957 agregaron a continuación del art. 14 de la Ley Fundamental -art. 14bis". Ello no obstante que dos de los jueces del Tribunal, en su disidencia parcial, señalaron que "La garantía constitucional a la libertad de contratar incluye su aspecto negativo, es decir, la libertad de no contratar que es un aspecto de la autonomía personal a la que todo ciudadano tiene derecho - art. 19 de la Constitución Nacional- y un supuesto del derecho a ejercer una industria lícita - art. 14 de la Constitución Nacional-, razón por la cual no se puede obligar a un empleador -contra su voluntad - a seguir manteniendo en su puesto a empleados - en el caso, despedidos por su actividad sindical- que no gozan de la confianza que debe presidir toda relación de dependencia"32.

A este antecedente, se le puede añadir otras dos sentencias del mismo Tribunal, las que, con matices, transitan en similar sentido: "Pellicori, Liliana Silvia c. Colegio Público de Abogados de la Capital Federal s/Amparo"33 y "Cejas, Adrián Enrique c. Fate S.A. s/juicio sumarísimo"34.

La articulación de estos tres casos en forma conjunta permite reseñar algunas conclusiones arribadas por la jurisprudencia suprema, tanto al momento de finalizar una relación contractual laboral (Alvares, Maximiliano c/Cencosud S.A., Pellicori, Liliana c/ Colegio Público de Abogados de la Capital Federal y Cejas, Adrián c/ Fate S.A.) como también al tiempo de celebrar una relación de similar carácter (Sisneros, Mirtha c/ Taldelva S.A.), en ambos casos a la luz de la no discriminación.

Así, al confrontar la libertad de empresa con el derecho a trabajar (sea al celebrar un contrato o bien al finalizarlo), de la jurisprudencia de la Corte Suprema de Justicia de la Nación surge que:

- quien fuera afectado por un acto discriminatorio y prima facie lo haya acreditado le asiste un estándar probatorio aplicable - reparto de la carga -, el cual traslada al demandado la carga de probar que como reprochado del acto tuvo como causa un motivo o criterio objetivo y razonable ajeno a toda discriminación;

- el ejercicio de la libertad de empresa - en todas sus manifestaciones-, encuentra su límite en la afectación del derecho a la no discriminación en la relaciones laborales;

- ese límite se manifiesta tanto en el ejercicio del derecho del empresario al finalizar una contratación (de trabajo), como así también al iniciar una contratación

\footnotetext{
32 Sentencia de la Corte Suprema de Justicia de la nación, "Álvarez, Maximiliano y otros c. Cencosud S.A." de fecha 07/12/2010, votos de las juezas Higton de Nolasco y Argibay. El subrayado es agregado.

${ }^{33}$ Sentencia de la Corte Suprema de Justicia de la nación de fecha 15/11/2011.

${ }^{34}$ Sentencia de la Corte Suprema de Justicia de la nación de fecha 26/3/2013, con las disidencias parciales señaladas en la cita $n^{\circ} 31$
} 
(de igual carácter), si su despliegue no puede ser encuadrado como un motivo objetivo y razonable y máxime si se violenta la igualdad real de oportunidades en perjuicio de uno de los colectivos señalados en el artículo 75 inciso 23 de la Constitución nacional.

¿Recortan estos estándares los alcances constitucionales de la libertad de empresa? No, de ninguna manera. Sencillamente reafirman que los derechos fundamentales pueden y deben - ser ejercidos en un marco constitucional y convencional, en donde la no discriminación y la igualdad real de oportunidades constituyen principios supremos ineludibles.

Resulta evidente que asistimos a un tiempo en donde el derecho constitucional se posiciona por sobre todas las relaciones jurídicas, verticales y horizontales, y que ningún acto de trascendencia jurídica puede ser validado si se encuentra motivado por una irrazonable diferenciación o discriminación.

En fin, esto no es otra cosa que aplicar la fuerza normativa constitucional y convencional en todos los ámbitos de la vida diaria.

\section{REFERÊNCIAS}

ALEXY, Robert. Teoría de los derechos fundamentales. Madrid: Centro de Estudios Políticos y Constitucionales, 1993.

BIDART CAMPOS, Germán. El derecho de la Constitución y su fuerza normativa. Buenos Aires: Ediar, 1995.

Tratado elemental de derecho constitucional argentino. t. I-B. Buenos Aires: Ediar, 2000 ?.

CAO, Christian. Constitución socioeconómica y derechos fundamentales. Estudio comparado entre los casos de España y Argentina. 2013. Tesis (Doctorado en Derecho) -Universidad Complutense de Madrid, Madrid. 2013.

El derecho a ganarse la vida mediante un trabajo y las reglamentaciones irrazonables. In: Revista Jurídica La Ley, Buenos Aires, 2011-B.

EKMEKDJIÁN, Miguel. Tratado de derecho constitucional. t. I. Buenos Aires: Depalma, 1993.

GIL DOMÍNGUEZ, Andrés. Escritos sobre neoconstitucionalismo. Buenos Aires: Ediar, 2009.

GUASTINI, Riccardo. Distinguiendo. Estudios de teoría y metateoría del derecho. Barcelona: Ariel, 1999.

HÄBERLE, Peter. Libertad, igualdad, fraternidad: 1789 como historia, actualidad y futuro del Estado constitucional. Madrid, Editorial Trotta, 1998.

JELLINEK, Georg. La Declaración de los Derechos del Hombre y del Ciudadano. México: Universidad Nacional de México, 2000.

PÉREZ HUALDE, Alejandro. Constitución y economía. Buenos Aires: Depalma, 2000. 
QUIROGA LAVIÉ, Humberto. Lecciones de derecho constitucional. Buenos Aires: Depalma, 1995.

SAGÜÉS, Néstor. Elementos de Derecho Constitucional. t. II. Buenos Aires, Astrea, 1997. 